\title{
Sonhos que cruzam fronteiras: sentidos construídos a partir do processo migratório ${ }^{1}$
}

ELIZARA GAROLINA MARIN"

REJANE DE OLIUEIRA POZOBON

\section{Resumo}

Este capítulo tem como objetivo desenhar um panorama sobre as vidas que cruzam fronteiras no que tange aos sonhos, antes e pós-migração, a partir da análise de relatos de migrantes de Porto Alegre e de Barcelona. Busca-se compreender a vida em trânsito e o projeto de retorno no processo migratório.

Palavras-chave: Migração. Sonhos. Projeto de retorno.

* Doutora em Ciências da Comunicação. Professora Adjunta da Universidade Federal de Santa Maria.

** Doutora em Ciências da Comunicação. Professora Adjunta da Universidade Federal de Santa Maria.

1 Este artigo está relacionado com a participação das autoras no Projeto Internacional Mídia e interculturalidade: estudo das estratégias de midiatização das migrações contemporâneas nos contextos brasileiro e espanhol e suas repercussões na construção midiática da União Européia e do Mercosul, desenvolvido em parceria entre a UNISINOS e o Observatorio y Grupo de Investigación en Comunicación y Migración (MIGRACOM) da Universidade Autônoma de Barcelona (UAB) com financiamento da CAPES (Brasil) e da Secretaria de Universidades del Ministério de Educación y Ciencia (Espanha). 
Sociologias, Porto Alegre, ano 12, no 24, mai./ago. 2010, p. 382-409

\section{Palavras iniciais}

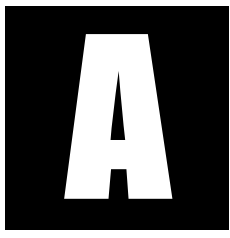

nalisar os sonhos - entenda-se projetos, desejos, motivações, aspirações, carências a serem satisfeitas - mobilizadores dos processos migratórios e o retorno ao país de nascimento, impõe-se a necessária compreensão de que o ser humano, em constante movimento, tem a especificidade de buscar a satisfação das suas necessidades e criar outras tantas no percurso da vida.

É importante assinalar, como conclui Gerd Bornheim (1995) na análise que realiza em Hegel e em Marx sobre a doutrina do desejo - que os sonhos se estruturam e processam dentro de coordenadas históricas e sociais. Significa dizer que a compreensão dos projetos dos migrantes não se reduz à instância puramente subjetiva, mas passa necessariamente pelas condições materiais e históricas que envolvem os sujeitos.

À luz do exposto, não é possível pensar os sonhos em trânsito sem situá-los no movimento da História (das regiões, dos países, dos continentes), pois, tanto estão relacionados com os contextos histórico-sociais, quanto efetivamente colaboram para o encaminhamento dos rumos da humanidade. Isso pode ser exemplificado por meio das palavras de Maldonado quando enuncia que o êxodo atual de milhões de latino-americanos para a Espanha mostra um dos aspectos cruéis do ordenamento estrutural neoliberal conservador de fundamentalismo de mercado (MALDONADO, 2005, p. 128). E entre os países da América Latina e os da União Européia, enlaçam respectivamente e de forma complementar, a problemática do êxodo e das transformações populacionais.

Este panorama nos instigou a analisar os sonhos e o projeto de retorno dos migrantes da América Latina e da Europa, residentes na cidade de Barcelona e em Porto Alegre. Para tanto, foram realizadas 70 entrevistas 
na cidade de Barcelona e 31 entrevistas na cidade de Porto Alegre, a fim de conhecer especificidades da experiência migratória e expectativas em relação ao projeto de retorno.

\section{Pensando o contexto}

As transformações populacionais, originárias fundamentalmente das experiências migratórias, trazem novos contornos para o contexto do globalismo. A globalização é definida por lanni (1999) como uma configuração histórico-social abrangente que convive com as mais diversas formas sociais de vida e trabalho, mas também que assinala condições e possibilidades, impasses e perspectivas, dilemas e horizontes. Trata-se de um processo de amplas proporções que, segundo o autor, "é produto e condição de múltiplos processos sociais, econômicos e culturais e resulta de um jogo complexo de forças que atuam em diferentes níveis da realidade, em âmbito local, nacional e mundial" (IANNI, 1999, p. 16).

O processo envolve nações, nacionalidades e grupos sociais. Pensamos que seja justamente no jogo entre o conjunto das estruturas configuradoras com as peculiaridades de cada indivíduo que compõem os mais distintos grupos, que as configurações sociais se vão desenhando. São realidades sociais, econômicas, políticas e culturais que se vão dinamizando com a globalização acelerada.

Pensar a globalização hoje é pensar a existência (e o convívio) de diferentes grupos e indivíduos, onde a diversidade e as semelhanças estão presentes no mesmo contexto. A globalização impõe fluxos importantes como as migrações, os conflitos étnicos e religiosos, entre outros. E a comunicação, por sua vez, tem a capacidade de conformar e compartilhar sentidos gerados nessa construção. Neste sentido, é importante lembrar que os processos globais vão sendo construídos pela circulação mais flui- 
da de capitais, bens e mensagens, mas também de pessoas que se deslocam entre os diferentes países do Globo. Incorporar o papel das pessoas e, portanto, a dimensão cultural do processo de globalização é, nas palavras de García-Canclini, "reconhecer o suporte humano desse processo, sem cair na redução dos movimentos econômicos a fluxos anônimos" (GARCÍA-CANCLINI, 2003, p. 58).

Portanto, mais do que uma ordem social ou um processo único, a globalização é o resultado de múltiplos movimentos, muitas vezes contraditórios. Trata-se de um fenômeno que acaba produzindo impacto, tanto no país de nascimento, quanto no país de imigração, pois "juntamente às tendências homogeneizantes, a globalização traz a proliferação da diferença" (HALL, 2003, p. 60). Esses efeitos diferenciadores emergem no interior das sociedades e entre as mesmas, "são sistemas de (con)formação da diferença" (HALL, 2003, p. 59), em vez de sinônimos de anulação das singularidades.

O que ocorre no fim do século XX, segundo lanni, é o intenso desenvolvimento do capitalismo mundial, dotado de movimentos próprios e abrindo e reabrindo fronteiras. "Trata-se de uma realidade social, econômica, política e cultural de âmbito transnacional” (IANNI, 1999, p. 20), que pode recriar as mais diversas formas de nacionalismos e localismos e, em geral, modifica o lugar e o entendimento de espaço e tempo. Como explica lanni, "desterritorializam-se e reterritorializam-se em outros lugares, em outras durações, as coisas, as gentes e as idéias. Também assim se transforma o mapa do mundo, não só o que pode estar na Geografia e na História, mas também o que pode estar nas mentes e corações" (IANNI, 1999, p. 21).

É possível afirmar que os migrantes entrevistados pelos investigadores do Brasil-Espanha traduzem essa compreensão de território, marcada por cruzamentos e por interstícios culturais, conforme nomina Bhabha (1998). Na concepção do autor, essa perspectiva possibilita deslocar as identidades da rigidez imposta pela polaridade (nós-outros) que foi cons- 
truída ao longo da modernidade. Possibilita também pensar este outro, a partir da negociação, dos interstícios culturais, o "terceiro espaço", como propõe Bhabha (1998).

Às vezes penso em português, às vezes penso em espanhol... No, no, no sei se tem... Dependo do quê acontece. E eu já tô com hábitos de brasileiros, né? Eu quando fui pro Uruguai pela última vez... As pessoas que eu procurei me diziam "tchê, mas como tu tá abrasileirado"! Eu não pude evitarlo, né? (Jaime, Porto Alegre, 55 anos, nascido no Uruguai).

No entanto, a ideia de formação de um inter-espaço, que não é mais o território do outro nem o nosso, não consegue dar conta de alguns posicionamentos assumidos por alguns imigrantes entrevistados nesta pesquisa. Em alguns casos, a idéia de hibridez, de um espaço que se forma a partir da interação e que aceita contribuições de outras culturas precisa ser questionada. "Tu vai criando raízes nesses lugares, mas logicamente não cria raízes porque tem certas coisas que te faz lembrar do que tu era do lado de lá" (Javier, Porto Alegre, 45 anos, nascido na Argentina).

Na concepção de Ribas Mateos (2004), é possível enumerar três adjetivos que ilustram o panorama que envolve a relação globalização e processos migratórios. De acordo com a pesquisadora, os movimentos migratórios são cada vez mais "intensos, diversificados e complexos". "Intensos", no sentido de que o número de migrantes que abandonam sua terra natal e cruzam diariamente as fronteiras é cada vez maior. Os motivos que ocasionam esse aumento são múltiplos e variados, vão desde as transformações da economia mundial, passam pelos movimentos étnico-religiosos e culminam na busca por melhores condições de vida. Esses movimentos são também cada vez mais diversificados. Isso pode ser verificado, segundo a autora, na feminilização do fenômeno migratório, por exemplo. Por fim, as migrações são cada vez mais complexas. Diferentes fatores dão conta desta complexidade dos movimentos migratórios, 
dentre eles, a autora destaca o fato de os fluxos não terem mais origem e destinos determinados, ocorrendo um vai-e-vem mais ou menos desordenado, em várias direções. Para Mateos (2004), os migrantes acabam acumulando em suas trajetórias de vida, várias saídas e várias chegadas, numa tentativa de se fixarem definitivamente.

\section{Os sonhos dos migrantes da América Latina e da Europa residentes na cidade de Barcelona}

A análise dos sonhos que movem sujeitos latino-americanos e europeus a se tornarem cidadãos em trânsito aponta claramente para o desejo de melhorar as condições de vida. Cabe destacar, porém, as diferenças entre os sonhos dos migrantes da América Latina e da Europa que residem em Barcelona, diferenças, diga-se, calcadas nos contextos sociais, econômicos e geográficos das regiões. Dos setenta migrantes entrevistados em Barcelona, dezessete são oriundos de diferentes países da União Européia. Os projetos que impulsionam a migração aparecem, na maioria das narrativas deste grupo, dissociados do econômico e ancorados na motivação profissional, cultural, turística, familiar e afetiva e além disso, no aprendizado de idiomas e no desejo de liberdade. Jimmy (24 anos), nascido na Inglaterra, e Rubén (47 anos), nascido na Itália, por exemplo, migraram para estarem mais próximos das suas namoradas, nascidas na Espanha e residentes em Barcelona. Também é o caso de Sara (53 anos), nascida na Alemanha e de Emma (45 anos), na Itália, que migraram para acompanhar seus maridos. Outro fator que move o trânsito desses migrantes assenta-se na identificação de Barcelona como uma cidade com forte expressão cultural e, portanto, viabilizadora de desenvolvimento profissional. Sara, por exemplo, migrou com o marido, por ambos acreditarem ser mais fácil encontrar trabalho na profissão de musicoterapeuta. 
Jisela (35 anos), nascida na Alemanha, também migrou com seu marido, da Alemanha para a Itália e posteriormente para Barcelona, almejando enriquecer a formação em publicidade principalmente como evidência, pela expressividade na arte contemporânea. A migração para Barcelona está mediada por um conhecimento prévio da cidade, que se estabeleceu através de relações de amizades, de experiências turísticas, de períodos de formação acadêmica ou de aprendizado de idioma.

Fundamentalmente a migração está revestida pelo desejo de conhecer outras culturas, de viajar, de mudar de vida e de morar na cidade que produz encantamento. Há que se dizer que o encantamento por Barcelona está alicerçado no fato de ser uma cidade que agrega vida cultural intensa (nas artes, na música, na arquitetura, no cinema, entre outros), diversidade cultural (convivência de vários povos e várias línguas), coroada por clima agradável, mar e praias. Pode-se dizer que esses migrantes identificam Barcelona como uma cidade ideal para se viver.

Vale assinalar, no entanto, a experiência de Telma que, nascida na Alemanha, após três anos de residência em Barcelona, passou a desconstruir o imaginário idealizado da cidade: “[...] antes pensaba que Barcelona era una ciudad ideal, y todo tan maravilloso no es. La gente es muy mal educada, muy antipáticos, en eso bueno los alemanes me parecen mejores. [...] Pero que no todos son así pero... hay muchas, que no saludan, la gente que no te abre la puerta". (Telma, Barcelona, 33 anos, nascida na Alemanha)

Para a maioria desses entrevistados, migrar não foi algo pensado e definido a priori, processou-se na medida em que foram estabelecendo interações com a cidade. Visível, por exemplo, na experiência de Carlota (30 anos), nascida na França, quando expõe que não havia projetos de residir em Barcelona, mas pouco a pouco foi sentindo-se cada vez melhor na cidade. 
No percurso das experiências e dos anos, pode-se dizer que os sonhos dos dezessete migrantes entrevistados se foram concretizando à luz do que assinala Julio, que nas suas aspirações pessoais, buscava qualidade de vida, relações humanas mais afetivas e condições de desenvolvimento profissional, não encontradas em Portugal:

E a viagem, as experiências estão valendo a pena. Eu analiso de uma forma positiva. Posso dizer que tive bastante sorte, não só pelas pessoas que eu conheci, durante esses dois anos, porque basicamente consegui uma certa independência financeira e profissional. Mas acho que Barcelona é muito produtivo, bastante além daquilo que eu poderia pensar. (Julio, Barcelona, 40 anos, nascido em Portugal)

Próximo aos projetos dos migrantes da América Latina os quais, em sua maioria está relacionado com a busca de melhores condições econômicas, o casal Robert (62 anos) e Anne (64 anos), ambos da França, migraram para Barcelona, com a aspiração de viver num país e numa cidade que lhes possibilitasse condições econômicas de sobrevivência. Também Susana (30 anos), nascida na Polônia, trouxe na bagagem a expectativa não apenas de viajar e conhecer outras culturas - para além do controle e da vigilância vivida em seu país por longos anos, devido aos conflitos políticos - mas também, o de trabalhar e ser reconhecida na sua profissão, condição inviável de ser alcançada no país de nascimento devido à crise econômica.

Além do destacado, fica visível que a opção dos migrantes europeus por Barcelona, tem relação com o fator geográfico, ou seja, com a proximidade com o país de nascimento, viabilizando visitas frequentes e, por conseqüência, o cultivo do sentimento de pertencimento e de enraizamento. Bem discute Milton Santos, por meio do que denomina de uma geografia da ação, que "os eventos, as ações não se geografizam indiferentemente. Há, em cada momento, uma relação entre o valor da ação e o valor do lugar onde ela se realiza" (SANTOS, 2004, p. 86). 
Os migrantes da América Latina que residem em Barcelona são procedentes de diferentes países, têm diferentes níveis de escolaridade e formação profissional, mas comungam do desejo de melhores condições de vida. Os sonhos que desencadeiam os trânsitos estão basicamente assentados na busca de alçar horizontes distantes dos conflitos políticos, de superar as dificuldades na esfera de trabalho - instabilidade no emprego, baixos salários, desemprego -, de sobreviver na profissão desejada, de morar e de estudar no exterior, de adquirir bens e montar um negócio particular. A migração é motivada pelo imaginário de que, no velho mundo, há estabilidade econômica, possibilidade de reconhecimento profissional, proximidade entre os países, permitindo a realização dos seus projetos.

Me vine a España, con la posibilidad de sacarse la seguridad social y esas cosas ino? Quería venir porque Europa me llamaba mucho la atención, por su historia y todo lo que significa ino? sobre todo para América, esa imagen que tenemos del continente viejo, del continente que tiene la experiencia [...]. Yo soy artista [...], mis expectativas es conseguir un trabajo un poco más a mi nivel, y poder hacer cosas que me agraden realmente, desarrollarme un poco más artísticamente. (Ramón, Barcelona, 46 anos, nascido na Venezulea) Bueno, el mayor deseo era vivir en un sitio donde la gente no estuviera tan pesimista. Y también un poco en ese momento las ganas de crecer, no. En Argentina siempre se idealiza mucho Europa y yo tenía un poco la ingenuidad esa de "querer conocer" Europa. [...]Me pareció una experiencia positiva. (Hugo, Barcelona, 44 anos, nascido na Argentina) Pues el principal objetivo [...] es ganar dinero. Pero siempre estableciéndome aqui [...] puesto que Europa tiene una economía más estable. En realidad yo vine con esa idea, de hacer mi vida aquí. De asentarme aquí, por la estabilidad que tiene Europa en general. Quizá poner un negocio más adelante. (Sebastián, Barcelona, 28 anos, nascido em Peru).

Diferentes dos europeus residentes em Barcelona, cuja opção se realiza para a maioria, por meio do contato anterior com a cidade através 
de turismo, para os migrantes da América Latina, a mediação para o projeto migratório se realiza por meio de parentes e amigos que residem em Barcelona e pela facilidade do compartilhamento do idioma espanhol ${ }^{2}$.

Conforme as narrativas dos cinquenta e três migrantes, o choque cultural vivido nos primeiros tempos, as dificuldades para encontrar trabalho e habitação, a falta de documentação, contrastam com o que lhes é informado pelos parentes e amigos e com o idealizado. Para a maioria, a experiência inicial é desalentadora, permeada pelo sacrifício, impelindo o adiamento dos projetos, que passa, em grande medida, pela legalização da documentação:

La expectativa era llegar y trabajar en un tiempo mínimo. En una fábrica, haciendo más o menos lo que hacía ahí [...]. Luego llegas, y la realidad es muy complicada ino? Porque está el tema legal por un lado, que piensas que se va a resolver rapidamente pero no es así. Te obliga a dejar tu sueño apartado para otro momento y hacer lo que el momento te permite, que eran clases particulares, nadie me pedía permiso de trabajo para hacer clases particulares. (Javier, Barcelona, 48 anos, nascido na Argentina).

Los sueños se van cumpliendo poco a poco y con mucho esfuerzo. Sí, me lleva más tiempo de lo que pensaba, pensaba que podía fluir mucho mas rápido, pero no. O sea, incluso mantener un trabajo estable, con un buen sueldo, implica un montón de esfuerzo. (Carmen, Barcelona, 27 anos, nascida na Argentina).

Yo esperaba venir aquí a trabajar, de pronto hacer... convalidar mi título, pero veo que es muy difícil, te exigen muchas cosas, entonces bueno, ahora solamente quiero trabajar, estoy estudiando inglés y luego regresar a mi país para poder seguir trabajando de maestra y ayudar a los niños más necesitados de mi país. (Lídia, Barcelona, 38 anos, nascida no Equador)

2 Vale assinalar que o catalão é o idioma oficial de Barcelona, todavia o idioma espanhol é amplamente utilizado pela população, até mesmo em virtude da presença representativa de migrantes de países latino-americanos. 
Se, por um lado, o que foi idealizado não se concretiza de imediato e na sua totalidade, quase todos, principalmente os migrantes residentes há mais de três anos, destacam que os sonhos se vão realizando com o passar do tempo, por meio da conquista de vantagens econômicas e profissionais, da possibilidade de estudar, de viajar e de auxiliar com remessas de dinheiro os familiares que ficaram.

Que cuando uno tiene voluntad y uno se ha traído una meta y uno se sacrifica, lucha por obtener esa meta. Porque ahora ya hemos comprado una casa, una casa de dos pisos que era nuestra aspiración, allá en Ecuador, ya tenemos... lo que falta es poco para terminarla y la meta que hemos traído, con sacrificio la hemos obtenido. (Fernando, Barcelona, 48 anos, nascido no Equador)

Com relação à realização dos sonhos, estabelecem comparações entre o país de nascimento e a Espanha e destacam deste as possibilidades maiores e melhores, e daquele, as crises econômicas e políticas:

Mi sueño era tener un taller de arte y lo tengo. Ese era mi sueño y bueno lo he cumplido. [...] Estoy bien, estoy haciendo más o menos cosas que me gustan .[...] Porque allá no me sentía del todo bien, [...]allá todas tus ilusiones, tus metas, tus logros que podrías hacer se iban abajo isabes? (Antonia, Barcelona, 30 anos, nascida na Colômbia)

Tengo sueño de conocer el mundo. Porque éste es el lugar donde uno puede hacer, cumplir sus sueños porque de donde yo vengo, de donde venimos, es muy difícil juntar un dinero para decir 'me voy a la India en dos meses más'. En cambio, aquí es facilísimo poder hacerlo. (Pedro, Barcelona, 35 anos, nascido no Chile)

Sobreviver era a minha primeira preocupação e acho que é um sonho, [...] e eu estou conseguindo cumprir e bem. [...] Acho que é um privilégio eu poder estar aqui, trabalhando com o que eu quero, vivendo razoavelmente bem, com a minha casa. [...] Eu estou satisfeito nesse caminho. Isso é uma coisa que eu gosto em Barcelona, aqui é uma dife- 
rença que eu vejo no Brasil, lá eu não conseguia planejar e viver da música. Então, dentro desse esquema, eu vejo super bem, eu estou muito melhor, [...] estou crescendo. (Damián, Barcelona, 32 anos, nascido no Brasil)

\section{Projeto de retorno}

As narrativas dos migrantes europeus, em sua maioria, evidenciam que não há projetos de retorno ao país de nascimento, principalmente daqueles com laços familiares estabelecidos em Barcelona.

Ni hablar. Bueno... no es verdad. Después de casarme, en el periodo previo a la boda, estuvimos buscando una casa en Francia, pero, visto los precios más las pensiones que vamos a tener, aquí se presenta una vida más relajada. En Francia, te sacuden demasiado los impuestos. Y la vida de los pueblos de Francia me parece aburridísima. (Anne, Barcelona, 64 anos, nascida na França)

"No, de verdad no tengo estos planes, simplemente pienso poder ir a otro sitio, más lejos. A mi me gusta moverme, no pienso quedarme en un sitio u otro, no pienso quedarme." (Emma, Barcelona, 45 anos, nascida na Itália)

Para alguns migrantes da América Latina residentes em Barcelona, não está no horizonte o projeto de retorno ao país de nascimento. $\mathrm{Na}$ experiência de Celso, por exemplo, em virtude dos projetos concretizados - viver na Espanha, trabalhar, quitar as dívidas no país de nascimento, conseguir permissão de residência e constituir família - não há projeto de retorno senão para realizar visitas.

Y aquí estoy muy bien y he cubierto mis deudas y he salvado mi casa, la hipoteca la hice con un prestamista, ahora mi casa la tengo alquilada... Ahora veo las cosas distintas pues aquí he formado una familia pues encontré mi señora y tengo una hija. Ahora solo pienso en vivir y trabajar para ella. Pienso 
volver a mi país pero de visita dentro de 8 meses o un 1 año con mi señora y mi, hija pero luego volveré aquí. Yo siempre llevaré a mi país en mi mente, no por estar en Europa dejo de ser ecuatoriano. No voy a renunciar a ser ecuatoriano por ser europeo. (Celso, Barcelona, 43 anos, nascido no Equador)

Todavia, para a grande maioria dos migrantes da América Latina, o retorno ao país de nascimento é um projeto acalentado. Projeto, diga-se, que pode ser adiado por longos anos, principalmente quando o processo migratório está associado às motivações econômicas: adquirir imóvel, montar empresa, investir na formação profissional e melhorar as condições materiais de existência no país de nascimento. Karen, de 22 anos, nascida no Brasil, sonha com o retorno, mas não antes de ter dinheiro suficiente para comprar uma casa no país de nascimento. Jorge tem como motivação ganhar dinheiro para, no retorno, montar um negócio próprio.

Yo creo que volveré cuando recoja dinero. Yo ya estoy un poco viejo para seguir trabajando para la peña, para hacer las tonterías que estoy haciendo. Tengo idea de poner un negocio. Estoy aburrido de trabajar para gente, para empresas. (Jorge, Barcelona, 37 anos, nascido no Chile)

Pode-se perceber, por meio dos relatos, que a temporalidade atua fortemente na realização dos projetos dos migrantes. Karen, por exemplo, reside em Barcelona há dois anos, Antônio está na cidade há nove anos e relata que, no plano econômico, realizou o seu sonho. Vale ressaltar, no entanto, que o tempo de residência e a consecução dos projetos, ainda que em parte no plano econômico, têm influência relativa sobre a decisão de retorno. As narrativas elucidam a tensão entre voltar e/ou ficar.

Faz-se necessário destacar que o projeto de retorno, à luz do que assinalam outros estudos (SIQUEIRA, 2007; DeBIAGGI, 2004), congrega como fator relevante, além das motivações econômicas, os aspectos subjetivos, tal como o reencontro com os laços identitários, com a família e com os amigos. 
Mira que España, Barcelona y Cataluña es muy bonito, a mi me gusta mucho. Pero los temas que me hacen regresar a Perú: es mi familia, ahí están mis padres, mi hermano, mis amigos, la comida, la comida es muy buena acá, pero la comida peruana... (Júlio, Barcelona, 27 anos, nascido no Peru)

O sentimento de nostalgia com o ninho (MAFFESOLI, 2001) acontece em virtude do país, da cidade, da aldeia, ou seja, do local físico de nascimento configurar como um refúgio para o sujeito. Ao mesmo tempo, a relação com o "ninho" é ambígua. Na profusão de sentidos novos e diferentes provocados pelo processo migratório, o sujeito já não é mais "o mesmo" de quando abandonou o ninho.

Bueno, estoy hace siete años aquí estoy un poco en un período de crisis. Pero no sé se volveré, porque otra vez es empezar de cero ahí, y a veces uno al revés se siente extranjero en su propio país. Creo que eso también es un sentimiento muy extraño, sentirse extranjero en su propio país. Y es quizá más duro ino? Entonces aún no lo tengo muy claro... (Meli, 31 anos, Barcelona, nascida na França)

Vale realçar, a partir do que assinala Hilário, nascido na Argentina e há dezoito anos em Barcelona, que o passar dos anos e o avanço da idade reafirmam o sentimento de retorno e o sonho de estar "com os seus", ou ainda, "com a sua gente". Quando solicitado sobre os planos de retorno, responde:

Sí, sí, sí. Por varias razones, primero porque es mi cultura y no la he perdido, no la he olvidado, no he renegado de ella. Luego porque la edad te va marcando una etapa, yo tengo 55 años. Tengo hermanos que son diez años mayores que yo. Mamá murió hace muy poquito, eh.. papá ya había fallecido hace mucho, y tengo sobrinos de 30 años que están teniendo hijos y yo me estoy perdiendo todo. $Y$ mis amigos tienen mi edad y en cualquier momento van a empezar a faltar. [...] Y quiero estar con ellos, quiero vivir la cotidianeidad. (Hilário, Barcelona, 55 anos, nascido na Argentina) 
É possível observar que o espaço-tempo da vida familiar e afetiva tem peso nas decisões de retorno nos processos migratórios, assim como a dimensão de nação e o sentimento de pertencimento a uma cultura, que vai desde a língua até a fenotipia. Mesmo que, conforme sugere GarciaCanclini (2003, p. 73), "os imigrantes atuais tenham mais possibilidades de manter uma comunicação fluida com o local de origem" por meio do uso das diferentes mídias, nos trânsitos entre o país de nascimento e o de residência, entre a instância subjetiva e as condições materiais e históricas que envolvem os migrantes, a decisão de retornar ou permanecer é conflituosa e recorrente na suas trajetórias.

\section{Os sonhos dos migrantes residentes na cidade de Porto Alegre - Brasil}

No contexto de Porto Alegre, o processo migratório ganha contornos diferentes para os imigrantes da Europa e da América Latina. No entanto, é possível observar uma questão que é comum ao imaginário dos imigrantes europeus e latino-americanos: a imagem de um Brasil construído a partir de um estereótipo tropicalista.

As falas dos migrantes latino-americanos e europeus evidenciam que existe uma expectativa em relação ao Brasil, construída tanto pelas experiências de turismo, quanto pela mídia. "Lamentavelmente a gente identifica assim: samba, mulatas e nada mais." (Laura, Porto Alegre, 62 anos, nascida no Chile)

A gente sabia coisas de futebol, dos grandes jogadores, que o brasileiro não é levado muito a sério, porque o brasileiro é muito malandro. Por exemplo, se ele está namorando, ele não pede em casamento, porque ele é muito liso, namora aqui, namora lá, mas é uma questão de conceito. (Javier, Porto Alegre, 45 anos, nascido na Argentina) 
A partir das narrativas dos sujeitos, é possível destacar algumas dimensões que, antes da migração, já mediavam os sonhos e os imaginários acerca do Brasil e dos brasileiros: o turismo, onde os pesquisados tiveram uma experiência positiva com o Brasil e os brasileiros, experiência esta que posteriormente se revelará distinta da experiência migrante; a mídia, que (re)constrói e divulga na cena pública representações acerca do país e sua gente e, em menor alcance, as redes de relações de amigos que também acabam trazendo referências sobre o "outro". "Conhecemos o Brasil pela publicidade, né! Pelas músicas, de repente... o que sai nos jornais, o que sai na tv, né. No meio de comunicação, tudo essas coisas, né!" (Rosa, Porto Alegre, 24 anos, nascida no Paraguai).

É interessante ressaltar que os imaginários acerca do Rio Grande do Sul e de Porto Alegre são formados a partir de cidades ou capitais brasileiras com características de turismo e com forte enfoque tropicalista, tais como Rio de Janeiro e as praias de Santa Catarina. "É uma coisa mais carioca, mais baiana. (...) "focado" para carnaval, para mulheres bonitas". (Fernando, Porto Alegre, 48 anos, nascido no Chile)

É porque lá (no Paraguai) só pensa no Brasil, así, é mais no que é Bahia, no que é Rio de Janeiro, todas essas praias, Florianópolis, toda a parte mais turísticas, né? Mas aqui no sul é mais frio, así. Não deu pra ir pra praia, e tudo assim. (Rosa, Porto Alegre, 24 anos, nascida no Paraguai)

Ribeiro (2002) reúne esses modos de representar o Brasil na categoria tropicalismo, onde o país é visualizado como a terra do carnaval, das mulheres bonitas, etc. Essa construção não é atual, o autor propõe que ela foi originada ainda nas primeiras narrativas sobre o Brasil. Explicita seus argumentos trazendo trechos de uma carta de Pedro Vaz de Caminha, num texto fundacional que descobre o Brasil e fala das primeiras mulheres que viu em terra. "Era tão bem feita e tão redonda, e sua vergonha (que ela não tinha) tão graciosa, que a muitas mulheres da nossa terra, 
vendo-lhe tais feições, fizera vergonha, por não terem a sua como ela" (RIBEIRO, 2002, p. 250).

A erotização das mulheres brasileiras evidenciada na carta de Caminha é uma construção ainda vigente e que está presente, em graus distintos, na fala de muitos migrantes entrevistados. Evidentemente, a visão estereotipada que os migrantes conformam ao longo dos tempos sobre o Brasil não se esgota na dimensão da sexualidade relacionada à mulher brasileira. Ela abrange outros âmbitos que englobam a música, os ritmos, a alegria e o futebol brasileiro.

O Brasil na época era ... agora, o Brasil é bastante difundido pelo mundo afora, porque o futebol, porque a Miss Universo, a Deise Nunes, sou do tempo da Deise Nunes, né... porque o futebol. Eu, em 83, quando fui pra lá, já era o ... principalmente, Porto Alegre, por causa do rei de Roma, o Falcão ${ }^{3}$. (Tamara, Porto Alegre, 55 anos, nascida na Itália)

Para os imigrantes latino-americanos, o imaginário tropicalista não é o único fator que transforma o Brasil em um importante destino do processo migratório. Existem duas outras razões que ganham destaque na decisão de emigrar: as dificuldades econômicas (como 'corralito', da Argentina) e episódios críticos da vida política (como as ditaduras no Uruguai e Chile).

Quando me vine para Brasil foi más que nada una questão econômica, tá! A situação do Uruguai econômica né. Desde aquela época só piorou não é? Y meu esposo recebeu una proposta de trabalho muito boa aqui, por eso nos vimos a morar aqui. (Margarita, Porto Alegre, 31 anos, nascida no Uruguai)

A gente ficou... Perdimos tudo. Perdimos o carro. Perdimos o apartamento. Perdimos as poupanças com o corralito. A gente perdió tudo, tudo, tudo. E meu filho de aqui, o brasileiro, chamando: "Vem para aqui, mãe! Vem para aqui,

3 Jogador de futebol brasileiro que jogou no Sport Club Internacional de Porto Alegre e na seleção brasileira 
mãe! Que aqui tu vai saber que a gente começa de novo, tu vais a ter uma chance...". Custou muito a tomar esta decisão, porque eu tenho dois filhos, de meu segundo matrimônio, que são argentinos, que não conheciam Brasil, que não conheciam a língua, que não sabiam nada do Brasil. Não sabiam. Só sabiam que tinha um hermano que morava no Brasil. Mas, finalmente, a coisa foi tão horrível, o que a gente passou, que decidimos mais uma vez, quando a coisa fica horrível na Argentina, vir para o Brasil. (Bárbara, Porto Alegre, 54 anos, nascida na Argentina)

No cenário político-social, era período de ditadura, muitas relações que se davam com estudantes e professores, policia e a sociedade eram muito marcantes, tu via muita agressão, eu mesmo tive muitos amigos que foram detidos sob averiguação, não tinham feito nada, mas estavam andando na rua, um deles que sumiu, e foram aparecer quatro dias depois, porque eles ficavam incomunicáveis, nem os pais sabiam onde eles andavam e isso era muito freqüente $t u$, ia para aula e um professor tinha sido detido, tinha levado um tiro, ou tinha sido torturado ou tinham matado alguém que era conhecido, então isso era uma coisa que, neste período, saiu vinte mil jovens do Uruguai, então juntou uma coisa com a outra e daí eu decidi vir para o Brasil eu não sei porque talvez, pela leitura que eu fiz do Brasil, que eu tinha conhecidos também existia a ditadura mas havia outro tipo de liberdade. (Wolf, Porto Alegre, 42 anos, nascido no Uruguai)

Sim o regime político, a ditadura militar que era muito rigorosa. E minha formação inicial era de Artista Plástico, então a gente tem uma exigência de liberdade individual, né, que a ditadura militar não permite. Além do sentimento social, do desgaste pela "pecha" do governo socialista, NE, e dos colegas presos e toda essa carga emocional né, que gera uma ditadura. (Fernando, Porto Alegre, 48 anos, nascido no Chile)

O que me levou primeiramente é o fator econômico, né. O Uruguai tava em ditadura ainda era muy ruim a vivência lá no Uruguai, né. Aí minha família, minha irmã, meu cunhado vie- 
ram para aqui primeiro né. Daí nasceu a minha sobrinha aqui, aí a minha idéia siempre, siempre foi querer sair do Uruguai, siempre gostei de sair. Aí me propus. Me propus eu e minha mãe. (Jana, Porto Alegre, 50 anos, nascida no Uruguai)

Para os europeus, a decisão de migrar vem associada à possibilidade de prosperar e ao entendimento de que trariam contribuições importantes para o país de imigração.

Por que nós imigramos de lá? Porque a situação na época, foi no pós-guerra, então não existia indústria, não existia terra para produzirmos, era um lugar pobre de trabalho e de alimentação. Então eu acho que foi motivo para todo o jovem sair fora, eu acredito que mais de 50\% de quem nasceu lá saiu para outros lugares do mundo, como os meus parentes África do Sul, França, Venezuela e Brasil. Tenho parentes espalhados por todos estes lugares. (...) Saíram sozinhos como eu saí, aventurando por uma vida melhor. (Jairo, Porto Alegre, 61 anos, nascido em Portugal)

Entre os migrantes latino-americanos, uma questão que também é salientada quando se referem à decisão de migrar é o sonho de conhecer outros países, "desbravar o mundo". Entre os migrantes europeus, entrevistados em Porto Alegre, essa questão não ganha destaque. "O meu sonho era viajar por toda a América Latina, né? Era meu sonho... Ir do Chile até a Centro América, né? Era meu sonho... Acho que sonho de muitos..". (Jaime, Porto Alegre, 55 anos, nascido no Uruguai)

Independente do país de nascimento, a decisão de migrar quase nunca é uma escolha tranquila. Mesmo que muitos entrevistados não vejam a migração como uma experiência profundamente dolorosa, é possível observar, a partir da análise de suas falas, que o processo implica, no mínimo, em mudanças estruturais e afetivas que, de alguma maneira, vão incidir na conformação de suas identidades e experiências migratórias. Alguns entrevistados, especificamente traduziram esse processo como uma decisão permeada de dor, dúvidas e inquietações, onde o momento 
político ou econômico vivido por estes sujeitos fez com que a emigração se convertesse na única solução possível.

No caso dos migrantes latino-americanos, a chegada ao país de imigração faz com que algumas expectativas sejam atendidas e outras, frustradas. Dentre as expectativas correspondidas observamos, entre os relatos dos entrevistados, a liberdade política alcançada no Brasil, a possibilidade de prosperar financeiramente e a boa receptividade dos brasileiros. Com relação às expectativas não atendidas, relacionadas às dificuldades vivenciadas no processo migratório, os entrevistados citaram os contrastes entre a experiência como turista e como migrante; a dificuldade com o idioma português; as diferenças gastronômicas; o permanente sentimento de estrangeiro. "Tu te encuentra dentro de uma realidad que es totalmente diferente. Aí, esa realidad, tu la cuestiona. Tu cuestionas la lengua, cuestiona los productos, cuestiona todas las cosas." (Luis, Porto Alegre, 60 anos, nascido no Chile) "Não é a mesma coisa ir de visita na casa de alguém, do que depois ir a morar na casa desse alguém." (José, Porto Alegre, 45 anos, nascido no Uruguai)

Respeitando as especificidades de todas as experiências migratórias que este texto contempla e vigilante quanto ao risco de promover generalizações, é perceptível o fato de que a diferença de posicionamento em relação ao sentimento de identificação com o Brasil e os brasileiros está relacionada à forma diferenciada como os migrantes são recebidos no país. Aliadas a isso, situam-se as diferentes experiências da migração, que não se encerram na chegada do migrante no país de imigração. Através da experiência migratória e, posteriormente, das relações socioculturais e das práticas comunicacionais, estes sujeitos vão construindo a idéia do que é ser migrante e o que é ser um migrante no Brasil.

Um estranhamento bastante ressaltado pelos migrantes entrevistados em Porto Alegre, tanto da Europa quanto da América Latina, é a condição do idoso no Brasil. Embora alguns entrevistados procedam de países eu- 
ropeus como Espanha e Itália, onde a experiência com os mais velhos é diferenciada, inclusive devido à significativa porcentagem de idosos na população do país, essa realidade chama a atenção de muitos entrevistados.

Eu acho que as classes mais abastadas não têm tanto, mas da classe média para baixo eu acho que têm muito, a pessoa pára de viver um pouco, fica muito recolhida em casa, eu acho isso aí. (...) Eu sinto assim, o espanhol pode ter 90 anos, mas ele vive muito na rua. Tu vê assim, não tem aquela coisa de tu ter uma idade e ser impedido de fazer a vida. Eu vejo aqui que as pessoas com 60 e poucos anos se recolhem, vivem uma vida já mais afastada. (Marta, Porto Alegre, 59 anos, nascida na Espanha)

Eu adoro o Brasil, amo muito o Brasil, mas uma coisa que eu enxergo muito é que o brasileiro é muito americanizado. Não que eu abomine os americanos, nada disso, mas no sentido de que busque uma própria identidade. O jeito descontraído, extrovertido, eu gosto muito do brasileiro, só que aquela coisa, aquele culto pelo corpo, demais, primeiro as aparências. Tu uma pessoa bonita, bem vestida, tu trata de um jeito, uma pessoa gorda, feia, tu não trata bem. Isso eu vi muito aqui. Também os velhos, de idade avançada, também sinto uma discriminação. Então isso eu acho que é alienação, é uma cópia do modelo americano, que a gente vê na TV. Então, isso aí, talvez eu faria críticas construtivas. Também tem coisas no Peru que eu acho que são bem meIhores aqui do que lá. Eles são extremamente conservadores, até demais, então chega a ter uma falsa moral. (Manuel, Porto Alegre, 38 anos, nascido no Peru)

Outra questão perceptível é que as políticas nacionais relacionadas à migração marcam a trajetória destes migrantes e restringem possibilidades de sobrevivência econômica. Essa problemática, muitas vezes, "empurra" para a construção de estratégias de sobrevivência e inserção profissional no âmbito do trabalho informal e não regulamentado. "Eu dou aulas particulares, dou aulas em casa a pessoas que querem aprender 
a tocar instrumentos". (Oscar, Porto Alegre, 36 anos, nascido no Peru) "Eu estou colocando uma lojinha, uma lojinha em casa. Eu vendo Avon e vendo produtos, jóias, essas coisas, não consigo parar em casa". (Nuria, Porto Alegre, 36 anos, nascida no Uruguai)

Então é uma maneira de divulgar a cultura. A pessoa que se interessa por alguma coisa, um símbolo peruano que eu vendo, que gosto de explicar quando a pessoa se interessa, também porque eu tenho que vender. (Mara, Porto Alegre, 34 anos, nascida no Peru)

\section{Projeto de retorno}

Chama a atenção quando alguns entrevistados afirmam que este é "um caminho sem volta", que aquele que sai de seu país abriu uma porta para o mundo e isso traz implicações para toda a sua vida. A partir dos relatos dos migrantes entrevistados pelos pesquisadores do Brasil-Espanha, é possível observar que o migrante vai adquirindo uma competência para migração. Especialmente após a primeira experiência de migração, estes sujeitos passam a revelar-se "aptos" para muitos e variados tipos de trânsito e capazes de viver em lugares distintos. "Faz muito tempo acho que virei um cidadão internacional" (Lorenzo, Porto Alegre, 40 anos, nascido no Peru).

O questionamento sobre as possibilidades de retorno ao país de nascimento mostra posicionamentos distintos frente à migração. Há aqueles que alimentam a expectativa de retorno para a terra natal e aqueles que buscaram construir uma nova vida no espaço em que passa a ser vivenciado o projeto migratório. "De voltar não, porque já fiz a minha vida aqui, me casei." (Evelin, Porto Alegre, 27 anos, nascida no Paraguai)

Então eu acho que lá é só pra... para passear. Eu falo ainda que eu amo meu país. E tomara que algum dia melhore. 
Mas eu não sei se algum dia voltaria pra morar lá e... eu acho já, que a minha vida está se fazendo aqui. (Serena, Porto Alegre, 24 anos, nascida no Uruguai)

Aqui visualizamos diferentes modos de posicionamento identitários: migrantes que, de alguma maneira, buscam reterritorializar-se no país de destino, alimentando-se de duas casas, e migrantes que se refugiam no passado e possuem um forte sentimento de enraizamento. Pensamos que estes posicionamentos distintos têm estreita relação com as condições econômicas que os migrantes têm hoje e com a acolhida versus discriminação dos autóctones.

Sayad explica que a migração é composta por uma dupla contradição:

não se sabe mais se se trata de um estado provisório que se gosta de prolongar indefinidamente ou, ao contrário, se se trata de um estado mais duradouro, mas que se gosta de viver com um intenso sentimento de provisoriedade (SAYAD, 1998, p. 45).

Assim, a migração seria o resultado de uma dupla representação: o estado provisório que a define como direito somado à situação duradoura que a caracteriza de fato.

Em algumas narrativas, fica explícito o "apagamento" ou não aceitação da forma definitiva que reveste o processo migratório, passando-se a levar em conta somente o caráter provisório (de direito). A análise das falas de alguns migrantes nos leva a pensar que, neste caso, a migração, para conseguir perpetuar-se e até mesmo se reproduzir, costuma ignorarse a si mesma (ou fingir que se ignora) e ser ignorada (ao não ser aceita como definitiva). Trata-se de uma contradição essencial que é inerente à própria condição de "ser migrante", ou seja, instala-se um imaginário coletivo de uma estada provisória (que pode durar indefinidamente) com a condição de que este "indefinidamente" jamais seja enunciado como tal.

Imigrante eu acho que é aquele que veio como...como... como colonizaram aqui no sul... Os europeus... Isso eu 
acho que foram imigrantes... Os que vêm do Uruguai, da Argentina, de outros lugares... não considero imigrantes. Eu não me considero um imigrante. (Jaime, Porto Alegre. 55 anos, nascido no Uruguai)

A experiência da migração mistura sonhos, afetividade, nostalgia e sentimentos que parecem, ainda hoje, não resolvidos. A estada num lugar, que alguns já tomam como seu e outros vêem como do "outro", permite um olhar mais atento ao passado e mostra história, memória e identidades em permanente construção. "Yo no me sinto espanhol, no me sinto ni argentino. Y quiero sentirme brasileiro e não me deixam." (Matias, Porto Alegre, 46 anos, nascido na Espanha). "Quando tu vai para um outro país tu adquires características daquelas pessoas, daquele povo, eu já não sou mais a mesma que saiu do Uruguai." (Serena, Porto Alegre, 24 anos, nascida no Uruguai)

Brasil puede ser muy bueno, pero ... como te puedo decir. Yo me siento aquí en Brasil sola. No sé si yo voltara... me siento también sola en mi país. Hemos intentado de qué forma podamos voltar, mas, hemos intentado de todas formas mantener vínculos con Chile mas, no está habiendo las posibilidades... (...) Y de ahí, siempre pensando en volver a Chile, mas..., no es como cuando salimos. Son gentes que ya no conoces más, otros fallecieron, otros se fueron. (Bea, Porto Alegre, 50 anos, nascida no Chile)

Sentimentos como estes fazem com que a compreensão das identidades migrantes perpasse o entendimento de histórias de vidas de sujeitos que retêm fortes vínculos com seus lugares de origem e são obrigados a negociar com as novas culturas em que vivem. Se nos questionarmos sobre as identificações, as distinções e os pertencimentos após a experiência migratória, veremos que é neste sentido que a migração reconfigura as identidades dos sujeitos, pois, no momento em que os mesmos estão transitando em diferentes espaços e culturas, inevitavelmente são 
impactados por essa vivência. São identidades que exigem uma revisão na relação passado/presente, exigindo compreendê-la em sua constante construção. Sobre essa questão, Hall (2003) nos lembra que, entre a idéia de unidade perdida e os conflitos vividos pelos sujeitos migrantes, há muitas questões a serem discutidas e desveladas.

\section{Considerações finais}

Fica evidente, a partir dos relatos de migrantes de Porto Alegre e de Barcelona, que os processos migratórios não se dão apenas dos países pobres para os desenvolvidos, e sim, desenham um panorama de múltiplos trânsitos e destinos. São migrantes de diferentes nacionalidades, idades, níveis de escolaridade e formação profissional que cruzam fronteiras, impulsionados por diferentes motivações - econômicas, profissionais, políticas, afetivas, familiares, turísticas, aventura, liberdade - todavia, comungam do sonho de melhorar as condições de vida.

O cenário político-econômico, ao mesmo tempo em que impõe movimentos migratórios, acaba incidindo de maneira bastante significativa na constituição destas identidades. É justamente a partir dessas experiências migratórias, singularizadas e relacionadas com as questões sociais, políticas e econômicas do país de nascimento e de migração, que os sujeitos pesquisados retiram seu referencial simbólico para se identificarem e se posicionarem. Como se trata de uma experiência que agrega caráter fluído e transitório na vida destes migrantes, os sonhos também estão em trânsito.

É possível perceber diferenças significativas entre os sonhos dos migrantes da América Latina e da Europa que residem em Barcelona. Os dezessete migrantes da União Européia relataram que os projetos que impulsionam a migração estão dissociados do fator econômico e ancorados na motivação profissional, cultural e afetiva. Além disso, também 
é questão relevante a identificação de Barcelona como uma cidade com forte expressão cultural e o fator geográfico, ou seja, com a proximidade com o país de nascimento, viabilizando visitas freqüentes e, por conseqüência, o cultivo do sentimento de pertencimento e de enraizamento. Observa-se que, com o tempo, o imaginário idealizado da cidade passa a ser desconstruído. Entretanto, essa desconstrução raramente implica projetos de retorno ao país de nascimento.

Os cinquenta e três latino-americanos entrevistados são procedentes de diferentes países, têm diferentes níveis de escolaridade e formação profissional, mas compartilham o desejo de obter melhores condições de vida. Em sua maioria, estão em busca da estabilidade econômica e do reconhecimento profissional. É perceptível que a mediação para o projeto migratório se realiza por meio de parentes e amigos que residem em Barcelona e pela facilidade do compartilhamento do idioma espanhol. Em relação aos sonhos migrantes, observa-se que, quase todos, principalmente os migrantes residentes há mais de três anos, destacam que os sonhos se vão realizando com o passar do tempo, por meio da conquista de vantagens econômicas e profissionais, da possibilidade de estudar, de viajar e de auxiliar com remessas de dinheiro os familiares que ficaram. Todavia, para a grande maioria dos migrantes da América Latina, o retorno ao país de nascimento é algo bastante almejado.

Em relação aos migrantes residentes em Porto Alegre, uma questão comum no imaginário dos imigrantes europeus e latino-americanos é a imagem de um Brasil construído a partir de um estereótipo tropicalista. As expectativas em relação ao Brasil são construídas, tanto pelas experiências de turismo, quanto pela mídia. Para os europeus, a decisão de migrar vem associada à possibilidade de prosperar e ao entendimento de que trariam contribuições importantes para o país de imigração. Para os migrantes latino-americanos, a decisão de migrar está relacionada ao sonho de conhecer outros países. 
No caso dos migrantes latino-americanos, a chegada ao país de imigração faz com que algumas expectativas sejam atendidas e outras, frustradas. Dentre as expectativas correspondidas está a liberdade política alcançada no Brasil, a possibilidade de prosperar financeiramente e a boa receptividade dos brasileiros. As expectativas não atendidas estão relacionadas aos contrastes entre a experiência como turista e como migrante; a dificuldade com o idioma português; as diferenças gastronômicas; o permanente sentimento de estrangeiro. Em relação ao projeto de retorno, é possível observar uma dualidade bastante heterogênea, há aqueles que alimentam a expectativa de retorno para a terra natal e aqueles que buscaram construir uma nova vida no espaço em que passa a ser vivenciado o projeto migratório.

\section{Dreams that cross borders: senses constructed from the migration process}

\section{Abstract}

This chapter aims to provide a picture of the lives that cross borders when it comes to dreams, before and after migration, from the analysis of reports provided by migrants from Porto Alegre and Barcelona. The objective is to comprehend the life in transit and the return project within the migration process.

Keywords: Migration. Dreams. Return project.

\section{Referências}

BHABHA, Homi K. O local da cultura. Belo Horizonte: Editora da UFMG, 1998. 395 p. BORNHEIM, Gerd. Da superação à necessidade: o desejo em Hegel e Marx. In: NOVAES, Adauto (Org.). O desejo. São Paulo: Companhia da Letras, 1995, 503 p. p. 143-154.

COGO, Denise. A cidadania nas interações comunicacionais e midiáticas das migrações contemporâneas em Porto Alegre e Barcelona. Logos, Rio de Janeiro, v. 1, n. 1, p. 24-37, Edição Especial 2005. 
DeBIAGGI, Sylvia Dantas. Homens e mulheres mudando em novos espaços: famílias brasileiras retornam dos EUA para o Brasil. In: DeBIAGGI, Sylvia Dantas; PAIVA, Geraldo José (Org.). Psicologia, E/Imigração e cultura. São Paulo: Casa do Psicólogo, p. 135-164, 2004.

GARCIA-CANCLINI, Néstor. A Globalização imaginada. Trad. Sérgio Molina. São Paulo: Iluminuras, 2003. 223 p.

HALL, Stuart. Da Diáspora: identidades e mediações culturais. Belo Horizonte/ Brasília: Editora da UFMG/Representação da Unesco no Brasil, 2003. 434 p.

IANNI, Octavio. A era do globalismo. In: OLIVEIRA, Flávia Arlanch Martins. Globalização, regionalização e nacionalismo. São Paulo: Editora da UNESP, 1999. 286 p.

MAFFESOLI, Michel. Sobre o nomadismo: Vagabundagens pós-modernas. Tradução: Marcos de Castro. Rio de Janeiro: Record, 2001. 205 p.

MALDONADO, A. E. Inter-relações culturais, midiatização, migração e globalismo. In: Logos: Comunicação e Universidade, v. 1, edição especial, 2005, Rio de Janeiro: UERJ, Faculdade de Comunicação Social, 2005, p. 122-134.

RIBAS MATEOS, Natalia. Una invitación a la sociologia de las migraciones. Barcelona: Bellaterra, 2004. 204 p.

RIBEIRO, Gustavo Lins. Tropicalismo e Europeismo: modos de representar o Brasil e a Argentina. In: FRIGERIO, Alejandro; RIBEIRO, Gustavo. Lins. Argentinos e Brasileiros: encontros, imagens e estereótipos. Petrópolis: Vozes, 2002. 271 p.

SANTOS, Milton. A natureza do espaço: técnica e tempo, razão e emoção. São Paulo: Editora da Universidade de São Paulo, 2004. 384 p.

SAYAD, Abdelmalek. A imigração ou os paradoxos da alteridade. Trad. Cristina Murachco. São Paulo: Editora da USP, 1998. 304 p.

SIQUEIRA, Sueli. O sonho frustrado e o sonho realizado: as duas faces da migração para os EUA. Nuevo Mundo Mundos Nuevos, Número 7, 2007. Disponível em: <http://nuevomundo.revues.org/document5973,html>. Acesso em: 01 jan. 2008.

Recebido: 01/08/2008

Aceite final: 22/09/2008 